reputation for veracity. The only solution to this dilemma is, of course, that those responsible should acknowledge that this potentially objective part of their case will be convincing only when there is much more material for analysis whose authenticity can be demonstrated.

For the time being, the analytical evidence falls far short of being compelling, at least within the professional community. The point can be simply put by means of the conventions of the scientific literature. Thus the State Department has agreed that $\mathrm{Dr}$ Mirocha and his colleagues may, if they wish, publish the results of their analyses in the scientific literature. (So, of course, they should do.) The abstract of an acceptable contribution to the literature along these lines might take the form:

We have analysed four samples of materials supplied by the State Department and have obtained the following results. . .

Referees would no doubt say that such a report was technically beyond reproach but of somewhat limited interest. But if the proposed publication has an abstract beginning:

We have analysed samples collected from four sites in South-East Asia soon after the use of chemical weapons . . . and have concluded that the Vietnamese have been using toxic agents derived from Fusarium species . . . .

the referees would be down on them like a ton of bricks. This does not imply that the State Department's case falls down but rather that even with the apparently objective evidence for it now adduced, the case remains largely circumstantial.

The State Department has not yet proved its case, but it has raised a question that cannot be ignored. It is in everybody's interest that it should be answered, and quickly. One of the most chilling passages in the State Department's report is the speculation - it is no more - that mycotoxins rather than more lethal agents have been used in South-East Asia because they lead to bizarre forms of death calculated to frighten away the survivors of attacks. (Certainly the refugee camps of Thailand have been full for months.) If indeed it has now been shown that chemical weapons like these do have some military value, the outlook is awesome not merely for the luckless people of Laos and Kampuchea but for the rest of us. The prospect that it might be possible to reach an agreement between the major military powers to outlaw the use of chemical weapons in future wars, and to abandon their manufacture, will clearly be diminished if some group of generals has it firmly in its collective head that such a treaty would be a military loss.

So what should be done? The United Nations group of experts should clearly be asked - and helped - to complete the study on which it has embarked. The practical need is that it should be able to make a more detailed investigation of the regions in South-East Asia in which mycotoxins are said to have been used. The Soviet Union, which has some influence with the government of Vietnam, should recognize that its own case - that the allegations are a pack of lies - could only be strengthened by an investigation on the spot. And the United States should understand that the glee with which it has accused the Soviets of complicity in whatever has been happening in South-East Asia is counterproductive. Thus it serves no purpose but to confuse, that the State Department's report says that techniques for manufacturing and spraying trichothecenes from the air have been developed in the Soviet Union without adding that the objective (fully described in the literature) has been to control the spread of fungi other than Fusarium and related genera in forests. One of the materials, the trichothecene $\mathrm{T}-2$, has even been canvassed as a rodenticide. (Nobody suggests that it would make sense to think of killing rats by spraying such a material from the air.)

What the State Department has not appreciated is that the question which it has legitimately asked will be regarded less seriously by those who alone can provide an objective answer if the statement of the problem is biased. The danger that the appearance of the State Department's document will be mistaken for a political ploy is in any case enhanced because the United States government is in the thick of persuading Congress to embark on the manufacture of binary chemical weapons in the form of the $155 \mathrm{~mm}$ artillery shell known as M687, rightly castigated last week by $\mathrm{Dr}$ Matthew Meselson of Harvard University (before a Senate subcommittee) as militarily pointless and politically inflammatory. At the same time, to be fair, President Reagan has asked that the United States delegation to the Committee on Disarmament in Geneva reopen discussions on measures to control chemical weapons. The zeal with which those talks are prosecuted will be a powerful determinant of people's willingness to answer the State Department's question.

\section{Professional propaganda}

\section{By what means should professional people, not only scientists, aim to influence public opinion?}

The professions have often been accused of indifference to the problems of the societies in which they are embodied, and there is substance in the charge. Now, when many industrialized states are faced with unfamiliar and serious economic crises, governments may often rightly grumble that academics are more concerned with their own skins than with the solution of the economic problems about them. Other professions are similarly indictable. During the housing boom of the 1960s, for example, architects built dwellings without recognizing that people might not want to live in them, while teachers have for decades taught in schools without paying sufficient attention to the fitness of the curriculum for their students' needs. Not all, however, is disappointment. In many places, the legal professions have taken the lead in linking the practice of the law more closely with social realities and needs, while physicians have done much to change people's attitudes towards health and disease. So is it not entirely to be welcomed that there has recently been a rash of professional groups taking a special interest in what may be the most serious of all contemporary social problems - the dangers of nuclear war?

The short answer, which is "no", appears to offend some of those concerned (see page 386). That professional people have a responsibility to contribute their special knowledge to the solution of general problems is not in dispute, but only the means by which they do so. Similarly, there is no question that when a profession is, broadly speaking, agreed about the social consequences of some circumstance lying largely within its field, it should declare itself. It would thus be shocking if physicians were silent about the probable consequences of smoking. Unfortunately, however, the dangers of nuclear war do not lie exclusively within the province of a single profession, while there can be very few professions that are in broad agreement within themselves about the steps be taken to head off the danger.

This is why the emergence of groups of architects, or teachers, or even scientists, with catchy acronymic titles "against nuclear war", is a misfortune. By suggesting that the whole of a profession is in some way united about what should be done, these groups give the general public a false impression. By being separate from the more broadly based groups of people with the same aims, they run the risk of over-simplifying important problems. Medical groups, for example, may fairly make fun of official plans for civil defence against nuclear attack, but it would be more constructive if they did so in the context of the appalling difficulties, political and otherwise, of avoiding dependence on nuclear weapons.

In Britain and elsewhere in Western Europe, the immediate question is not whether nuclear war would be devastating everybody is agreed on that - but whether individual governments should to some degree opt out of present arrangements for the defence of Europe. Another question is the basis on which arms control agreements might be negotiated. Professional groups usually profess no opinion on such practical questions, preferring to stay within the confines of their professional competence. The result is that, by what they say, they influence general opinion irrationally or at least subliminally. This is why they are open to the charge of deceit. 